\title{
Dissolution Kinetics of pH Responsive Alginate-Pectin Hydrogel Particles
}

Jingxin Guo and Gönül Kaletunç*

Department of Food, Agricultural, and Biological Engineering, Ohio State University, Columbus, OH, United States

\section{Corresponding author:}

Address: 590 Woody Hayes Dr., Columbus, OH, US. 43210

Email: Gönül Kaletunç: kaletunc.1@osu.edu

Keywords:

Alginate, Pectin, $\mathrm{pH}$ responsive, biopolymer, Mechanical properties, Stability 


\section{ABSTRACT}

Encapsulation is used for protection of bioactive compounds during processing, storage, and passage through the upper gastrointestinal (GI) tract and delivery to the small intestine. A number of $\mathrm{pH}$ responsive synthetic polymers are approved for drug delivery but are not allowed for food applications. We developed a biopolymer mixture composed of alginate and pectin that can form hydrogel when the $\mathrm{pH}$ is below 3.0. We also produced novel disc shaped particles which can potentially enhance the particle adhesion in intestines. As the $\mathrm{pH}$ increases, Al-P hydrogels go through a gel-sol transition and the dissolution kinetics of the hydrogel dominates the bioactive compound release. The goals of this study are to investigate the relative effects of factors contributing to the dissolution kinetics of Al-P hydrogel and to develop mathematical models characterizing the degradation behavior of the hydrogels under product storage and lower GI tract conditions. The volume change of spherical and disc shaped particles at $\mathrm{pH} 3.0$ showed that the hydrogel particles would be stable in low $\mathrm{pH}$ beverages during storage. At $\mathrm{pH} 5.0$ and 7.0, hydrogel particle dissolution followed a zero-order kinetic model. The $2.8 \%$ TGC $43: 57 \mathrm{wt} \%$ Al-P disc particles had the fastest and the 2.2\% TGC 82:18 wt\% Al-P spherical particles had the slowest volume dissolution rate at $\mathrm{pH} 7.0$ and $37^{\circ} \mathrm{C}$. Activation energies of hydrogel particles were significantly affected by $\mathrm{pH}$, particle shape and $\mathrm{Al}$ to $\mathrm{P}$ ratio. Such a smart biopolymer system which responds to $\mathrm{pH}$ provides an opportunity to use food as a vehicle for targeted delivery of bioactive compounds. 


\section{Introduction}

Hydrogels have been investigated for delivery of nutrients and drugs in food and pharmaceutical industries and building scaffolds and sensors in medical applications. A variety of synthetic and natural polymers of hydrophilic properties were used as encapsulant to form hydrogels (Peppas et al, 2006). In food applications, FDA requires that encapsulant materials should have the “Generally Regarded As Safe (GRAS)” status. Typically, encapsulation occurs by physical entrapment of bioactive materials within the polymer networks of hydrogel, thereby inhibiting interactions between encapsulated material and external environment (Kuang et al., 2010). Then, hydrogel particles of biopolymer origin, containing bioactive materials can be incorporated in the food material for delivery of beneficial compounds to the human body. Encapsulant provides a protection to the bioactive molecules by isolating them from external environment encountered during food processing, storage, and human stomach (Anal \& Singh, 2007; Cabane et al., 2012; Drusch, 2007). It is also expected that upon reaching intestines, hydrogels should swell or dissolve so that beneficial compounds can be released in human body. Such "smart polymer" systems which are sensitive to physical and chemical stimulants were developed for controlled delivery of nutrients and drugs.

A number of protein and polysaccharides were used alone or in combination to form hydrogels (Wang et al., 2012). Numerous natural polysaccharides including agar, alginate, carrageenan, pectin, gelatin can form hydrogels under different conditions, and are considered as GRAS (FDA, 2015). Their biocompatibility and biodegradability are advantageous as delivery media applied in the food industry. The hydrogels formed by these materials have been produced (Burey et al., 2008; Ré et al., 2009) by different encapsulation techniques. Droplet extrusion is a fabrication method where in a biopolymer solution is extruded through an opening into a curing solution. 
The morphology and dimension of the resultant Ca-alginate particles were shown to depend on the flow rate of the feed solution, the diameter of the opening, surface tension and the viscosity of the polymer solution (Burey et al., 2008; Chan et al., 2009). The typical dimension of the hydrogel particles fabricated by this technique is $0.5-6 \mathrm{~mm}$ with or without combining other techniques (Burey et al., 2008). Smaller hydrogel particles were reported to be generated with the droplet extrusion method combined with other techniques, such as electrostatic dripping, laminar jet breakup, jet cutting, jet nebulizer and disk nebulizer (Ré et al., 2009).

Sodium alginate and pectin are anionic polysaccharides which form biodegradable hydrogels (Wang et al., 2012). Alginate comprises both guluronic acid (G) and mannuronic acid (M), and pectin only galacturonic acid. The abundant carboxylate and hydroxyl groups in both alginate and pectin result in a high hydrophilicity, which leads to polymer chain extension by the charge repulsion and to a high absorption of water (Oakenfull \& Scott, 1984; Wang et al., 2012). The gelation of alginate or low methoxyl (LM) pectin requires the presence of divalent cations, while high methoxyl pectin (HM) requires sugar (Thom et al., 1982; Walther et al., 2004); however synergistic gelation of alginate-pectin mixtures occurs at low $\mathrm{pH}$ reported between $\mathrm{pH} 3.3$ and 4 by various researchers depending on alginate-pectin ratio and $\mathrm{G} / \mathrm{M}$ of alginate and degree of esterification (DE) of pectin (Higuita-Castro et al., 2012; Toft et al., 1986; Thom et al., 1982; Toft, 1982; Morris \& Chilvers, 1984; Rao \& Cooley, 1995; Walkenström et al., 2003). Morris \& Chilvers (1984) reported that alginate or pectin did not gel under the same conditions that alginate-pectin blend formed a gel. Alginate: pectin mixtures have been used to encapsulate vitamin C, anthocyanins (Higuita-Castro et al., 2012) and folic acid (Madziva et al., 2005). Madziva and co-workers (2005) used an alginate and pectin gel mixture dropping into 0.1 to 1.0M of calcium chloride to fabricate hydrogel particles. Higuita-Castro and co-workers (2012) 
showed alginate-pectin hydrogel particles were formed while $\mathrm{pH}$ dropped from 6.0 to 3.0 by adding Glucono- $\delta$-lactone to biopolymer solution. However, the controlled dissolution of hydrogels is very important for release of incorporated bioactive compounds.

Dissolution of ionic alginate hydrogels was shown to be controlled by the biopolymer molecular weight, composition or the conditions of surrounding environment (Augst et al., 2006). Several studies exist in literature for dissolution behavior of alginate and pectin only gels (Bajpai \& Sharma, 2004; Kikuchi et al. 1999; Lee \& Mooney, 2012; Master et al., 1995; Sriamornsak \& Nunthanid, 1998; Xing et al., 2003; Thakur et al., 1997; Lopez da Silva and Rao, 2006). Although, biopolymer blend hydrogels such as Al-P can provide more opportunities for applications of environmental stimuli responsive drug and nutrient delivery, the factors influencing their fabrication and dissolution characteristics have not been elucidated.

The $\mathrm{pH}$ responsive characteristic distinguishes Al-P hydrogel from alginate or pectin only hydrogels since neither of them alone form a $\mathrm{pH}$ responsive gel. As the $\mathrm{pH}$ increases, $\mathrm{Al}-\mathrm{P}$ hydrogels are expected to go through a gel-sol transition and the kinetic of this transition can be a key factor in controlled release of bioactive compound. Several factors including temperature, alginate to pectin ratio, and the $\mathrm{pH}$ of the medium contribute to the dissolution of the hydrogel. The goals of the current study are to evaluate the effect of the encapsulation parameters; the alginate-pectin ratio, flow rate, dripping distance, and $\mathrm{pH}$ of curing solution on the morphology and mechanical properties of the hydrogel particles and to investigate the relative effects of the factors contributing to dissolution kinetics of Al-P hydrogel particles. The findings are used to develop mathematical models characterizing the dissolution behavior of the hydrogels at $\mathrm{pH} 5.0$ and 7.0, the environment that can be associated with a full stomach and the small intestine and 
colon respectively (Kong \& Singh, 2008; Guerra et al., 2012). The results of dissolution kinetics of hydrogels can be used for design of hydrogel based nutrient delivery systems.

\section{Materials and methods}

\subsection{Materials}

Alginate (SF 120) was obtained from FMC Biopolymer (Philadelphia, PA). Gluronic to mannuronic acid ratio $(\mathrm{G} / \mathrm{M})$ of alginate was 1.7 . High methoxyl content pectin (Pretested $^{\circledR}$ Pectin, rapid and slow-set) were provided by TIC Gum (White Marsh, MD). Rapid set pectin had a degree of esterification (DE) 71-75\% and slow-set pectin had a DE of 63-67\%. Reagents (hydrochloric acid, potassium chloride, citric acid, sodium citrate, sodium phosphate monobasic and sodium phosphate dibasic) to prepare buffer solutions of $\mathrm{pH}$ 1.2, 3.0, 5.0 and 7.0 were purchased from Fisher Scientific (Waltham, MA).

\subsection{Preparation of gel solutions}

Each of $2 \%(\mathrm{wt})$ alginate (Al) and $4 \%(\mathrm{wt})$ slow and $4 \%(\mathrm{wt})$ rapid pectin (P) solutions were prepared by dispersing the powders in deionized water with a high shear mixer for 30 minutes at ambient temperature. After incubating at $4{ }^{\circ} \mathrm{C}$ for 8 hours to allow bubbles to rise, the individual solutions were mixed in various ratios to obtain the desired total gum concentration (TGC) and 
Al to $\mathrm{P}$ ratios. The mixtures then were stored at $4{ }^{\circ} \mathrm{C}$ for an additional 12 hours for bubbles to rise. For screening experiments, Al-P mixtures of 2.2-3.0\% (wt) TGC and Al-P weight percent ratios of $33: 67,43: 57,67: 33$, and 82:18 were prepared. Pectin amount in the mixture was equally divided between slow and rapid set pectin.

\subsection{Hydrogel particle preparation}

The Al-P solutions were extruded through a $0.337 \mathrm{~mm}$ diameter $(23 \mathrm{G})$ needle (Hamilton, Nevada) with a peristaltic pump (Cole Parmer, IL) at volumetric flow rates of 0.017 or 0.022 $\mathrm{ml} / \mathrm{s}$. The droplets extruded through the needle formed hydrogel particles when they came into contact with gently agitated low $\mathrm{pH}$ buffered solution. $0.1 \mathrm{M} \mathrm{pH} 1.2 \mathrm{HCl} / \mathrm{KCl}$ buffer or $\mathrm{pH} 3.0$ citric acid/sodium citrate buffer were prepared as curing medium for hydrogel particles. For screening experiments, the curing buffers of $\mathrm{pH} 1.2$ or 3.0 , dropping distances of $1.5-20 \mathrm{~cm}$, AlP solution flow rates of 0.017 or $0.022 \mathrm{ml} / \mathrm{s}$, TGC of $2.2-3.0 \mathrm{wt} \%$ and $\mathrm{Al}$ to $\mathrm{P}$ ratios stated in section 2.2 were used to evaluate their effects on particle size and shape. Al-P hydrogel particles were cured at $4{ }^{\circ} \mathrm{C}$ for 2 hours prior to characterization of the dimensions and shape. Based on focusing the study on regular shaped particles and relatively higher gel strength, the conditions at Al to $\mathrm{P}$ ratio of $82: 18 \mathrm{wt} \% \mathrm{Al}-\mathrm{P}$ at $2.2 \mathrm{wt} \%$ TGC and 43:57 wt\% Al-P at $2.8 \mathrm{wt} \%$ TGC in pH 1.2 curing buffer were selected for for further studies. Throughout the text, 82:18 wt\% Al-P mixture at $2.2 \mathrm{wt} \%$ TGC is referred as formulation $1(\mathrm{~F} 1)$ and 43:57 wt $\%$ Al-P mixture at $2.8 \mathrm{wt} \%$ TGC is referred as formulation $2(\mathrm{~F} 2)$. 


\subsection{Particle size and shape characterization}

A digital microscope (Amoeba Dual Purpose Digital Microscope, Celestron, CA) was used to photograph hydrogel particles placed on a microscope slide at 10X magnification. Top and side view images of the hydrogel particles were obtained. The particle dimensions were determined using Image $\mathbf{J}$ software (National Institutes of Health, Bethesda, MD).

\subsection{Gel mechanical properties}

\subsubsection{Sample preparation}

Hydrogel cylinders under four combinations of 43:57 and 82:18\% (wt) Al to P ratio and 2.2 and $2.8 \%$ (wt) TGC were prepared to measure gel strength and elasticity. The gel solutions were mixed and poured into a plexiglass tube of $1 \mathrm{~cm}$ internal diameter and $1 \mathrm{~cm}$ height. One end of the tube was sealed with parafilm, and the tube was filled with the mixture from the open side. The tube was placed vertically inside a beaker filled with $40 \mathrm{ml}$ of $\mathrm{pH} 1.2$ buffer solution to promote gel formation. After 1.5 hours, an adequately thick gel layer formed on the open side. Then the parafilm was removed and the tube was inverted to expose the other end to the curing solution for 1.5 hours. The tube was placed horizontally in the curing solution to allow the buffer solution to diffuse into the gel from both ends. After 2 hours, the gels were ready for mechanical property tests. 


\subsubsection{Gel mechanical properties measurement}

Mechanical properties of cylindrical gels with the dimensions of $1 \mathrm{~cm}$ diameter and $1 \mathrm{~cm}$ height were determined using Texture Analyzer (TA.XTPLUS, Hamilton, MA). A stainless steel cylinder probe with $40 \mathrm{~mm}$ diameter was used at a speed of $0.2 \mathrm{~mm} / \mathrm{s}$. Gel samples were compressed to determine gel strength and strain at the point of failure. Force versus deformation data were recorded. Then the data were converted to corrected stress, $\sigma_{C O R}$, and Hencky's strain, $\epsilon_{H}$, as defined below (Kaletunç et al., 1991a):

$$
\begin{aligned}
\sigma_{C O R}(t) & =\frac{F(t)\left[H_{0}-\Delta H(t)\right]}{A_{0} H_{0}} \\
\epsilon_{H}(t) & =\ln \left[\frac{H_{0}}{H_{0}-\Delta H(t)}\right]
\end{aligned}
$$

where $H_{0}$ is the height of the gel specimen at time zero, $\Delta H(t)$ is the absolute deformation at time $t$, and $A_{0}$ is the cross-sectional area of the gel specimen at time zero.

Gel strength, $\sigma_{C O R}$ at failure, and $\epsilon_{H}$ at failure were determined from the stress-strain curve. The deformability modulus, $E_{D}$, was determined as the slope of the initial linear portion of the stressstrain curve as defined by Eq. (3):

$$
E_{D}=\frac{\sigma_{C O R}(t)}{\epsilon_{H}(t)}
$$

Elasticity of the gels was determined from four successive compression-decompression cycles at deformation levels of 10,15 and 20\%. The deformation levels for the elasticity test were selected 
to prevent the gel from reaching the breaking point. The threshold force was set at $10 \mathrm{~g}$ to determine the starting point of the compression experiments. The degree of elasticity was defined as the ratio of recoverable work to total work for each compression-decompression cycle. The total work was calculated as the area under the stress-strain curve of the compression cycle and the recoverable work was calculated as the area under the stress-strain curve of the decompression cycle (Kaletunç et al., 1991b).

\subsection{Particle stability study}

The stability of disc and spherical shape hydrogel particles of F1 and F2 formulations prepared in $\mathrm{pH} 1.2$ buffer solution was investigated as a function of time at temperatures 4,24 and $37{ }^{\circ} \mathrm{C}$, and at pHs 3.0, 5.0 and 7.0. For each experiment, hydrogel particles were removed from curing solution using a filtration funnel with vacuum and washed with a $\mathrm{pH} 1.2$ buffer solution to remove the residual gel solution followed by characterization of shape and dimension by microscope. Then, ten hydrogel particles were transferred into $6 \mathrm{ml}$ of $\mathrm{pH} 5.0$ or 7.0 buffers and agitated at $400 \mathrm{rpm}$. Particle size was monitored as a function of time over a $30 \mathrm{~min}$ period in the pH 5.0 or 7.0 buffers. At selected time intervals, buffer was replaced with a pH 1.2 buffer to stop further dissolution. Then, the particles were removed from the solution and the hydrogel particle size was measured. Experiments for particle stability in $\mathrm{pH} 3.0$ buffer were conducted over a 23

day period. All beakers and solutions were sterilized using UV light to prevent microbial growth during the long term storage. Each experiment was performed in triplicate. 


\subsection{Data analysis}

\subsubsection{Statistical analysis}

The statistical analysis was conducted to assess the variance among the replicates using ANOVA (analysis of variance), and the comparison of volume dissolution rate constants at different $\mathrm{pHs,}$ gel ratios and hydrogel particle shapes applying the $t$ test and Tukey's HSD (Honest significant difference) test using JMP for Windows, release 10 (SAS Institute Inc., Cary, N.C.).

\subsubsection{Calculation of activation energy}

The kinetics of hydrogel particle dissolution on a volume basis were evaluated by fitting both zero-order (Eq. (4)) and first-order (Eq. (5)) kinetic models to the data collected at pH 5.0 and 7.0.

$$
\begin{gathered}
V_{(t)}=V_{0}-k_{0} t \\
\operatorname{Ln}\left(V_{(t)}\right)=\operatorname{Ln}\left(V_{0}\right)-k_{1} t
\end{gathered}
$$

where $k_{0}\left(\mathrm{~mm}^{3} / \mathrm{s}\right)$ is the rate constant for zero order rate expression and $k_{1}$ is the rate constant $(1 / s)$ for the first order rate expression. $V_{(t)}$ and $V_{0}$ are the volumes of the hydrogel particles at time $t$ and zero, respectively. The dependence of the dissolution rate constant on temperature was described by the Arrhenius equation. The overall equation expressing volume change of 
hydrogel particles as a function of time and temperature for a zero-order kinetic model is defined as in Eq. (6).

$$
V_{(t)}=V_{0}-A t \exp \left(-\frac{E_{a}}{R T}\right)
$$

where $A$ is frequency factor $\left(\mathrm{mm}^{3} / \mathrm{s}\right), E_{a}$ is activation energy $(J), R$ is universal gas constant $\left(8.314 \mathrm{~J} \cdot \mathrm{mol}^{-1} \cdot \mathrm{K}^{-1}\right)$ and $T$ is absolute temperature $(K)$.

The $E_{a}$ and $A$ values were calculated at each condition of $\mathrm{pH}, \mathrm{Al}$ to $\mathrm{P}$ ratio and shape by the nonlinearfit function in MATLAB (R2015b, The MathWorks Inc., MA).

\subsubsection{Dependence of activation energy on $\mathrm{pH}, \mathrm{Al}$ to $\mathrm{P}$ ratio, and shape of the hydrogel particles}

A second order model was applied to analyze the activation energy dependence on $\mathrm{pH}$, alginate content, hydrogel particle shape and their interaction terms (Montgomery, 2008). In the model, the hydrogel particle shape was considered as a discrete factor (spherical was level 1 and disc was level 2), while alginate content and $\mathrm{pH}$ were considered as continuous factors and were coded as -1 and 1 . The $0.82 \mathrm{wt}$ fraction of alginate in gel mixture for F1 was coded as -1 , while $0.43 \mathrm{wt}$ fraction alginate in gel mixture for $\mathrm{F} 2$ was coded as 1 . $\mathrm{pH} 5.0$ was coded as -1 and 7.0 as 1. The final model is expressed by Eq. (7):

$E_{a}=\beta_{0}+\beta_{1} * p H+\beta_{2} * A l+\left\{\begin{array}{l}\tau_{S_{1}} \\ \tau_{S_{2}}\end{array}+\left(\beta_{12}\right) * p H * A l+\left\{\begin{array}{l}\tau_{p H S_{1}} * p H \\ \tau_{p H S_{2}} * p H\end{array}+\left\{\begin{array}{l}\tau_{A l S_{1}} * A l \\ \tau_{A l S_{2}} * A l\end{array}+\varepsilon\right.\right.\right.$ 
where $E_{a}$ is the activation energy, the predicted variable; $\mathrm{pH}$ and alginate fraction (Al) are the independent continuous variables; $S_{1}$ and $S_{2}$ are the discrete variables, sphere and disc shape; $\beta$ is the coefficient of continuous variables and $\tau$ is the coefficient of discreet variable or the coefficient of discrete variable-continuous variable interaction term. Specifically, $\beta_{0}$ is the offset term; $\beta_{1}$ and $\beta_{2}$ are coefficients for $\mathrm{pH}$ and $\mathrm{Al}, \beta_{12}$ is the coefficient of $\mathrm{pH}$ and alginate content interaction term; $\tau_{S_{1}}$ and $\tau_{S_{2}}$ are coefficients of spherical and disc shape, respectively; $\tau_{p H S_{1}}$ and $\tau_{p H S_{2}}$ are the coefficients of interaction term of $\mathrm{pH}$ and hydrogel particle shape; $\tau_{A l S_{1}}$ and $\tau_{A l S_{2}}$ are the coefficients of the interaction term of alginate content and hydrogel particle shape; and $\varepsilon$ is the statistical error due to other sources of variability such as the system error. Each pair of

discrete factor coefficients $\left(\tau_{S_{1}}\right.$ and $\tau_{S_{2}} ; \tau_{p H S_{1}}$ and $\tau_{p H S_{2}} ; \tau_{A l S_{1}}$ and $\tau_{A l S_{2}}$ ) is constrained to a sum equal to zero (Montgomery, 2008). Equation 7 was solved by using JMP software (SAS Institute, 2015) based on minimizing the sum of the squares of the difference between the calculated and the predicted values.

\section{Results}

\subsection{Preparation of hydrogel particles}

Preliminary experiments for particle preparation were conducted at four $\mathrm{Al}$ to $\mathrm{P}$ ratio, at four TGC, at two flow rates, at two drop heights, and at two curing bath conditions. Screening based on gel strength showed that gel samples cured in $\mathrm{pH} 1.2$ buffer solution had considerably greater gel strength (1.5-2 times) than those cured in $\mathrm{pH} 3.0$ buffer solution (data not shown). Therefore, 
only the hydrogel particles cured in $\mathrm{pH} 1.2$ buffer were used for further hydrogel particle characterization. Further screening based on the particle shape showed that under six conditions well defined spherical or disc shaped hydrogel particles were produced. Four of those conditions were associated with the same flow rate of $0.022 \mathrm{ml} / \mathrm{s}$. Therefore, four sets of hydrogel particles of spherical and disc shape prepared from F1 and F2 formulations were used for the stability studies. Specifically, the four sets included the disc shaped hydrogel particles produced using F2 at $5 \mathrm{~cm}$ drop height, $\mathrm{F} 1$ at $20.0 \mathrm{~cm}$ drop height and the spherical hydrogel particles generated using F1 at $5 \mathrm{~cm}$ drop height and $\mathrm{F} 2$ at $1.5 \mathrm{~cm}$ drop height.

Spherical hydrogel particles formed using F1 and F2 had a diameter of $2.68 \pm 0.24 \mathrm{~mm}$ and $2.76 \pm 0.10 \mathrm{~mm}$ respectively. The disc hydrogel particles generated by using F1 had $2.88 \pm 0.17$ $\mathrm{mm}$ diameter and $1.40 \pm 0.12 \mathrm{~mm}$ thickness while $\mathrm{F} 2$ produced disc hydrogel particles of $3.22 \pm 0.15 \mathrm{~mm}$ diameter and $1.63 \pm 0.15 \mathrm{~mm}$ thickness. The disc hydrogel particles produced using F2 were $12 \%$ larger in diameter and $16 \%$ larger in thickness than the ones produced from F1. Photographs of representative samples for both spherical and disc shaped hydrogel particles are shown in Figs. 1a, 1b, and 1c.

The shape of the hydrogel particles studied were affected by a combination of factors including the distance between needle and curing bath surface, alginate-pectin ratio and the flow rate. At the same flow rate and $\mathrm{Al}$ to $\mathrm{P}$ ratio, as the drop height increased the shape of the hydrogel particles produced changed from sphere to a disc for both F1 and F2 formulations. The change of shape to disc occurred at a higher drop height for F1 hydrogel particles than F2 hydrogel particles. Chan et al. (2009) developed mathematical models describing the effects of viscous and surface tension forces versus impact and drag forces on the shape of Ca-alginate particles. At the total gum concentration range investigated in this study (2.2-2.8\%), surface tension values 
are expected to stay approximately constant. Therefore, viscous forces should be the determining factors for the hydrogel particle shape. The F1 formulation had nearly two times greater viscosity than the F2 formulation, 2 Pa's versus 1.2 Pa·s. For the higher viscosity F1 formulation, the longer distance increases the momentum of a falling drop so that impact force between the drop and the surface of the curing bath is greater creating a deformation on droplet surface resulting in the change in shape from a sphere to a disc. Depending on the physical properties of solutions, drop height can be used to control the shape of the hydrogel particles.

\subsection{Mechanical properties of hydrogel particles}

Mechanical properties of gels at Al to P ratios of 43:57 and 82:18 at each TGC of $2.2 \%$ and $2.8 \%$ were determined to investigate the effect of TGC and Al to P ratios on the gel strength, strain at failure, modulus and total work at failure (Table 1). The TGC did not show any significant effect on gel strength for the same Al to $\mathrm{P}$ gel ratio, while increasing TGC significantly $(p<0.05)$ reduced the strain at failure and increased the modulus for both $\mathrm{Al}$ to $\mathrm{P}$ ratios. The extent of increase of modulus by TGC depended on the Al to P ratio. For 43:57 Al-P gels, the modulus did not increase significantly with TGC, while for high alginate content gels, the effect of TGC on modulus was significant $(p<0.05)$. The work required to break the gels decreased with increasing TGC. The higher strength of the high pectin gels can be related to the chemical interaction between alginate-pectin chain and hydrogen ions. It was reported that the gelation of alginate-pectin solution at low $\mathrm{pH}$ condition was affected by the content of methyl esterified Dgalacturonic acid in pectin and L-guluronic acid residues in alginate (Thom et al., 1982). 
Because pectin used in this study had high methyl ester content and alginate contained high guluronic acid residues, F2 gel may have a greater inter-chain interaction between alginate and pectin chains than the lower pectin content gel prepared using F1 formulation. A proposed explanation for the interaction between alginate and pectin chains at low and high $\mathrm{pH}$ conditions is shown in Fig. 2. For high guluronic acid content alginate and high methoxylated pectin chains, the $\mathrm{pH}$ decrease does not greatly affect pectin chains because of the high $\mathrm{COOCH}_{3}$ groups, but decreases electrostatic repulsion due to the protonation of $\mathrm{COO}^{-}$groups to $\mathrm{COOH}$ in both alginate and pectin chains. Decreasing $\mathrm{pH}$ does not affect either hydrogen bonding between $\mathrm{OH}$ groups or hydrophobic interactions and attractive forces become dominant due to reduced repulsive electrostatic forces. The effect of interaction between alginate and pectin chains on gel strength was higher than the influence of increasing total gum concentration. On the other hand, a greater strain at failure associated with a higher work observed for F1 gels indicates that F1 gels have less resistant to deformation than F2 gels (Table 1). This finding is consistent with the result that for the $\mathrm{F} 2$ formulation a shorter distance is needed to form a disc shaped particle. For F2 hydrogels, a higher stiffness (modulus - material's resistance to deformation) can be attributed to greater interaction between the alginate-pectin chains.

Elasticity of the hydrogels was studied as it can be related to the ability of hydrogel particles to return to their original shape after potential deformation during food processing (Figs. 3a and 3b). The total work is used to analyze the elasticity of the hydrogel particles because even if the hydrogel returns to the original dimensions, the total mechanical work may not be recoverable (Kaletunç et al., 1991b). The total work required increased with increasing deformation levels for both formulations. For 10 and 15\% deformation levels, both formulations exhibited a similar total work (Fig. 3a). However, at 20\% deformation level, total work was higher for F1 than F2. 
During the successive compression-decompression cycles, the total work remained unchanged at 10 and $15 \%$ deformation levels. At $20 \%$ deformation level, the total work increased after the first compression, but thereafter remained constant for both formulations. The degree of elasticity of gels is defined as the percent of recoverable work after a compression (Fig. 3b). Recoverable work was approximately $80 \%$ at a $10 \%$ deformation level for both F1 and F2. The two formulations exhibited different response of elasticity to increasing deformation levels. While the elasticity of gels steadily decreased at 15 and $20 \%$ deformation for F2 gels, elasticity of the F1 gels decreased at $15 \%$ deformation and remained constant at $20 \%$ deformation. In all the gels, the magnitude of the percent recoverable work decreased with the applied deformation increased indicating that increasing deformation weakens the structure of the gels and causes a loss of elasticity. Statistical analysis showed that the percent recoverable work was constant over the four cycles for both formulations at $10 \%$ deformation level.

The total work stayed approximately constant for four successive compression-decompression cycles suggesting that the elasticity of the gels do not change when they are subjected to small deformation levels. Similar behavior, characteristic of an elastic material, was reported for agar, alginate and kappa-carrageenan gels of similar concentration (Kaletunç et al., 1991b). Nonelastic materials, such as cheese or ripe banana showed a large decrease of total work at even deformation levels of $12.5 \%$ (Kaletunç et al., 1991a).

\subsection{Stability of hydrogel particles as a function of $\mathrm{pH}$ and temperature}


Stability of hydrogel particles is quantified in terms of volume change under various $\mathrm{pH}$ conditions. The volume change of hydrogel particles were investigated under various $\mathrm{pH}$ and temperature combinations, simulating low $\mathrm{pH}$ beverages $\left(\mathrm{pH} \mathrm{3.0)}\right.$ at refrigeration $\left(4^{\circ} \mathrm{C}\right)$, a full stomach (pH 5.0) and intestines $(\mathrm{pH} 7.0)$ at $37^{\circ} \mathrm{C}$. Comparison of hydrogel particle volume changes at the three $\mathrm{pH}$ conditions showed that while the volume of hydrogel particle remained constant over a period of 3 weeks at $\mathrm{pH} 3.0$ and $4{ }^{\circ} \mathrm{C}$, the hydrogel particle volume decreased over a significantly shorter time scale of less than 10 minutes at $\mathrm{pH} 5.0$ and 7.0 at $37^{\circ} \mathrm{C}$ (Figs. $4 \mathrm{a}$ and $4 b)$.

\subsubsection{Stability of hydrogel particles at low pH}

Low $\mathrm{pH}$ beverages are appropriate delivery vehicles for hydrogel particles containing bioactive compounds. Therefore, stability of hydrogel particles in terms of volume change at $\mathrm{pH} 3.0$ was investigated for 23 days. Experimental results did not show any dissolution of encapsulant material at $\mathrm{pH}$ 3.0. Swelling of hydrogel particles was observed with the volume change depending on the formulation of the hydrogel particles. Fig. 5 shows the hydrogel particle volume changes for both F1 and F2 formulations and for both spherical and disc shaped hydrogel particles at $4^{\circ} \mathrm{C}$ and at $\mathrm{pH}$ 3.0. Similar results were observed for the hydrogel particles at all temperatures investigated. A maximum swelling of $15 \%$ for $\mathrm{F} 1$ formulation was observed for spherical hydrogel particles at $24^{\circ} \mathrm{C}$. F2 hydrogel particles exhibited as high as $50 \%$ swelling for

disc shaped hydrogel particles at $24^{\circ} \mathrm{C}$. For all other conditions, F2 hydrogel particles exhibited a swelling of 30 percent or less measured after 8 days of storage with a residual swelling of 15 percent or less after 23 days (data not shown). Swelling was more significant for F2 hydrogel 
particles than F1 hydrogel particles. The results are in agreement with the scheme shown in Fig. 2. As the $\mathrm{pH}$ increases the hydrogen ion concentration decreases thereby deprotonating carboxyl groups and leading to swelling of high pectin gels, more than high alginate gels. The stability of the hydrogel particles in $\mathrm{pH} 3.0$ buffer under all three temperatures confirmed their possible application in low $\mathrm{pH}$ beverages under refrigeration conditions and at room temperature. Particles were also subjected to a temperature of $72^{\circ} \mathrm{C}$ for 15 seconds to simulate pasteurization conditions, which resulted in a minimal, 0.3 4.7, percent volume decrease. A similar result for heat resistance of $\mathrm{HM}$ pectin $(60 \sim 75 \% \mathrm{DE})$ and alginate $(\mathrm{M} / \mathrm{G}=0.53)$ mixed gel was reported by Toft (1982) as only $5 \%$ gel strength loss after an heat treatment at $80^{\circ} \mathrm{C}$ for $30 \mathrm{~min}$.

\subsubsection{Stability of hydrogel particles above pH 5.0}

Hydrogel particles dissolved as a function of time above $\mathrm{pH} 5.0$ as shown in Figs. 4a and 4b for $\mathrm{F} 2$ hydrogel particles at $\mathrm{pH} 7.0$ and $37^{\circ} \mathrm{C}$. Above $\mathrm{pH} 5.0$, the hydrogel dissolution rate was not highly depended on $\mathrm{pH}$, as dissolution rates at $\mathrm{pH} 7.0$ were approximately 1.1-1.5 higher than at $\mathrm{pH}$ 5.0. The dissolution rate of both disc and spherical hydrogel particles increased with increasing temperature. Comparison of Figs. $6 \mathrm{a}$ and $6 \mathrm{~b}$ indicates that disc hydrogel particles dissolved faster than spherical hydrogel particles at all temperatures investigated. Dissolution rate constants were found to be affected by $\mathrm{pH}$, temperature, hydrogel particle shape and $\mathrm{Al}$ to $\mathrm{P}$ ratio as outlined in Table 2. The $\mathrm{Al}$ and $\mathrm{P}$ chains open due to electrostatic repulsion when $\mathrm{pH}$ is above 5.0. Higher $\mathrm{pH}$ increases the amount of $\mathrm{COO}^{-}$and $\mathrm{COOCH}_{2}^{-}$groups and further enhances the electrostatic repulsion between alginate and pectin chains (Toft et al., 1986). Above pH 5, the 
dissolution of the Al-P hydrogel is expected to contribute to the release of the encapsulated compound as demonstrated by an experimental observation of decreasing volume as a function of time at $\mathrm{pH} 5.0$ and $4{ }^{\circ} \mathrm{C}$ for spherical $\mathrm{F} 1$ hydrogel particles containing purple corn anthocyanin (Fig. 7).

Volume dissolution rate constants changed between $3.8 \times 10^{-3} \mathrm{~mm}^{3} \cdot \mathrm{s}^{-1}$ and $65.5 \times$ $10^{-3} \mathrm{~mm}^{3} \cdot \mathrm{s}^{-1}$ depending on the formulation and environmental conditions. Under lower GI tract conditions of $\mathrm{pH} 7.0$ and $37^{\circ} \mathrm{C}, \mathrm{F} 2$ hydrogel particles are expected to have $2 \sim 2.5$ times higher volume dissolution rate constants than F1 hydrogel particles of the same shape due to the effect of formulation. The dissolution of the hydrogel particles at $\mathrm{pH}$ above 5.0 may be attributed to disruption of interactions between alginate and pectin because dissolution happened at a faster rate for high pectin F2 hydrogels than high alginate F1 hydrogels. Lowering the total gum concentration of high pectin gels to $2.2 \%$ increased the volume dissolution rate constant of spherical hydrogel particles to $17.6 \mathrm{~mm}^{3} / \mathrm{s}$ and $18.6 \mathrm{~mm}^{3} / \mathrm{s}$ at $24{ }^{\circ} \mathrm{C}$ and at $\mathrm{pH} 5.0$ and 7.0 respectively. Although both $\mathrm{TGC}$ and $\mathrm{Al}$ to $\mathrm{P}$ ratio affected the dissolution rate, $\mathrm{Al}$ to $\mathrm{P}$ ratio has a relatively higher influence on the rate constant than TGC (Table 2).

For the same formulation, spherical hydrogel particles had lower volume dissolution rate constants than their disc counterparts under all $\mathrm{pH}$ and temperature conditions. The specific surface area of disc and spherical particles were calculated by normalizing the particle surface area by the volume of the particles (Geankoplis, 2003). The specific surface areas were $2.24 \mathrm{~mm}^{-}$ ${ }^{1}$ and $2.17 \mathrm{~mm}^{-1}$ for $\mathrm{F} 1$ and $\mathrm{F} 2$ spherical particles, while they were $2.82 \mathrm{~mm}^{-1}$ and $2.47 \mathrm{~mm}^{-1}$ for F1 and F2 disc particles. A relatively lower specific surface area for spherical particles than for the disc particles can be associated with the lower dissolution rate for the spherical particles. As a result, a higher dissolution rate is expected from the disc particles. A comparison of diameter 
and thickness change for disc hydrogel particles showed that the diameter dissolution rate constants were significantly $(p<0.05)$ higher than the thickness dissolution rate constants (Table 3). Similarly, a comparison of diameter dissolution rate constants of disc and spherical hydrogel particles show that at the same $\mathrm{pH}$, formulation and temperature, the diameter change of disc hydrogel particles had a higher rate constant than that of spherical hydrogel particles (Table 3). For comparison of diameter and thickness dissolution rates for a disc shape particle, for a same volume loss corresponding diameter and thickness changes were calculated and compared. The results showed the specific surface change in the lateral direction of the disc particles was higher than the specific surface change in vertical direction leading to a larger decrease in diameter in comparison with the thickness. The observed results indicate that the geometry of the hydrogel particles affected the dissolution rate constant and the findings can be explained in terms of the specific area differences.

\subsubsection{Modeling dissolution of hydrogel particles at high $\mathrm{pH}$ as a function of time and temperature}

Dissolution behavior of the disc and spherical hydrogel particles produced from $\mathrm{F} 1$ and $\mathrm{F} 2$ at $\mathrm{pH}$ 5.0 and 7.0 followed a zero order kinetics at 4,24 or $37^{\circ} \mathrm{C}$ (Figs. $6 \mathrm{a}$ and $6 \mathrm{~b}$ ). The volume dissolution rate increased significantly $(p<0.05)$ with temperature for each $\mathrm{Al}$ to $\mathrm{P}$ ratio, hydrogel particle shape and $\mathrm{pH}$ (Table 2).

The effect of the temperature on hydrogel particle dissolution rate constant followed the Arrhenius Equation at both $\mathrm{pH} 5.0$ and 7.0. The fitting of the equation describing volume change 
of hydrogel particles as a function of time and temperature (Eq. (6)) showed that activation energies of hydrogel particles varied between 27.11 and $39.02 \mathrm{~kJ} / \mathrm{mol}$ indicating that hydrogel particles with different formulations and shapes, and in different $\mathrm{pH}$ environments had different sensitivities to temperature (Table 4). F2 hydrogel particles in general had higher sensitivity to temperature than F1 hydrogel particles at pH 5.0 and 7.0. The higher sensitivity of the F2 gels to temperature may be due to the higher pectin content, because pectin is reported to be sensitive to temperature change as hydrogen bonds and hydrophobic interactions between pectin molecules are believed to decrease as temperature increases (Oakenfull \& Scott, 1984).

\subsubsection{Modeling of the effect of alginate: pectin ratio, $\mathrm{pH}$ level and hydrogel particle shape on activation energy}

The activation energy of hydrogel particle dissolution depended on $\mathrm{Al}$ to $\mathrm{P}$ ratio, $\mathrm{pH}$ and hydrogel particle shape as shown in Table 4. For the same $\mathrm{pH}$ and hydrogel particle shape, alginate: pectin gel ratio affected the activation energy of F2 hydrogel particles dissolution significantly $(p<0.05)$ more than for $\mathrm{F} 1$ hydrogel particles. Effect of $\mathrm{pH}$ on the activation energy did not follow a specific trend as only the F1 disc hydrogel particles showed a higher activation energy at $\mathrm{pH} 7.0$ compared with $\mathrm{pH}$ 5.0. The activation energy of hydrogel disc hydrogel particles dissolution was higher than that for spherical hydrogel particles at the same $\mathrm{pH}$, except for the F1 hydrogel particles.

The activation energy data were fitted to a general second order model including a first order dependence of individual variables and their interaction terms. Fitting of the experimental data to 
Eq. (7) followed by $F$ tests demonstrated that interaction terms of $\mathrm{pH}^{*}$ alginate content and $\mathrm{pH}^{*}$ shape were not statistically significant because the probability values were 0.10 and 0.77 , respectively. After omission of the statistically non-significant terms, the general equation simplifies to Eq. (8):

$$
E_{a}=39.29+0.99 * p H-19.96 * A l+\left\{\begin{array}{c}
-4.59 \\
4.59
\end{array}+\left\{\begin{array}{c}
5.90 * A l \\
-5.90 * A l
\end{array}\right.\right.
$$

The $F$ test was used to determine the probability that the full model (Eq. (7)) and the simplified model (Eq. (8)) yield different residuals—-the differences between the calculated and predicted $E_{a}$ values as described by Kaletunç (2007). The probability of equivalent fits by full and simplified models to the $E_{a}$ calculated values is 0.64 , indicating the omitted terms do not contribute significantly and the simplified model can be used to predict the $E_{a}$ values for this particular data set. The model for prediction of $E_{a}$ also provides means to determine the significance of each factor $(\mathrm{pH}$, hydrogel particle shape and $\mathrm{Al}$ to $\mathrm{P}$ ratio) and their interaction terms on the activation energy. The probability that the factors are highly significant in affecting activation energy was 0.0024 for hydrogel particle shape, less than 0.0001 for $\mathrm{Al}$ to $\mathrm{P}$ ratio, and 0.001 for $\mathrm{pH}$, which are all significantly smaller than $\alpha=0.05$.

The proposed simplified model can be used to predict the activation energy for $\mathrm{pH}$ between 5.0 and 7.0, alginate fraction from 0.43 to 0.82 and for either spherical or disc shaped particles. Equations 6 and 8 were combined into Eq. (9) to express the volume change of hydrogel particles as a function of time, temperature, particle shape, $\mathrm{pH}$ and alginate fraction.

$$
V_{(t)}=V_{0}-A * t * \exp -\left(\frac{39.29+0.99 * p H-19.96 * A l+\left\{\begin{array}{c}
-4.59 \\
4.59
\end{array}+\left\{\begin{array}{c}
5.90 * A l \\
-5.90 * A l
\end{array}\right)\right.}{R * T}\right)
$$


Eq. 9 was used to determine the calculated volume change and the calculated values were plotted against the corresponding experimental volume change (Fig. 8). The relationship between the calculated and experimental volume change are described by a linear equation with slope of 0.98 , intercept of 0.004 and a correlation coefficient of 0.91. All data points appeared to be closely scattered around the perfect predictive equation shown by the green solid line. The average absolute error between the calculated and experimental values was determined to be $11.9 \%$ within the two dashed lines displayed for the 24 data set used (Fig 8).

These results can be used to predict the dissolution of Al-P hydrogels under various $\mathrm{pH}$ and temperature conditions that may be related to the release of encapsulated compounds in the hydrogels. The dissolution rate of hydrogels can be predicted based on the position of the hydrogel particles in the GI tract. For fastest dissolution at $\mathrm{pH} 7.0$ and $37^{\circ} \mathrm{C}, \mathrm{F} 2$ hydrogel particles with disc shape should be used, because $70 \%$ of such hydrogel particles are expected to dissolve within $2.5 \mathrm{~min}$. For slowest dissolution of hydrogels at $\mathrm{pH} 7.0$ and $37^{\circ} \mathrm{C}, \mathrm{F} 1$ hydrogel particle with spherical shape should be used, because $70 \%$ of such hydrogel particles are expected to dissolve within $7 \mathrm{~min}$.

Based on the kinetic model, $40 \%$ of the four types of hydrogels used in this study dissolved within 3-7 min after hydrogel particles were exposed to $\mathrm{pH} 5.0$ at $37^{\circ} \mathrm{C}$ which is the expected environment of a full stomach. Given that the residence time reported for liquid products in the stomach is around $20 \mathrm{~min}$ (Collins et al., 1991) and can be up to 3 hours for solid products (Guerra et al., 2012), hydrogel particles in a beverage at pH 3.0 or lower should be consumed with an empty stomach so that hydrogel particles can be delivered intact to the intestine. To this end, Al-P hydrogel particles have the potential to be used as $\mathrm{pH}$ responsive drug or nutrient delivery vehicles based on the dissolution kinetics at $\mathrm{pH} 5.0$ and 7.0. Further studies are 
necessary to quantify the relative effects of diffusion and hydrogel dissolution on the release of various bioactive compounds.

\section{Conclusions}

Alginate-pectin hydrogel particles can be prepared either in spherical or disc shape by extrusion of mixed biopolymer solution into a $\mathrm{pH} 1$ buffer for use in food applications. The $\mathrm{Al}$ to $\mathrm{P}$ ratio, dripping solution flow rate, and dropping distance affected the hydrogel particle shape and size. Al-P hydrogel particles maintained their integrity at $\mathrm{pH} 3.0$ or below but dissolved as a function of time above $\mathrm{pH} 5.0$ as described by a zero order kinetic model. The dissolution was accelerated with temperature 4-6 times between 4 and $37{ }^{\circ} \mathrm{C}$ as defined by the Arrhenius relationship. An empirical modeling of activation energies showed that hydrogel dissolution is highly affected by particle shape, $\mathrm{Al}$ to $\mathrm{P}$ ratio, and $\mathrm{pH}$. The shape of the hydrogel particles is expected to influence the attachment of the hydrogel particles to the intestinal wall. The findings also revealed that the Al-P hydrogel dissolution rates were highly influenced by the shape of the particles thereby controlling the delivery of an encapsulated bioactive compound.

The dissolution rate of hydrogel is proposed to be an important contributor to release rate of the bioactive material in the GI tract. Further studies are ongoing in our laboratory to quantify the release rates of bioactive compounds by diffusion versus by dissolution at $\mathrm{pH}$ above 5.0. The kinetic modeling as a function of time and temperature, and further characterization of kinetic parameters as a function of biopolymer ratio, $\mathrm{pH}$ and hydrogel particle shape will allow us to achieve more precise design of $\mathrm{pH}$ responsive hydrogel delivery systems with desired 
mechanical and dissolution properties necessary for encapsulation and controlled release of bioactive compounds.

\section{Acknowledgement}

This project was supported by Agriculture and Food Research Initiative Grant \#2012-67017-

30169 from the USDA National Institute of Food and Agriculture, Improved Processing

Technologies program-A1351, and the Food Innovation Center (The Ohio State University,

Columbus, $\mathrm{OH})$ grant. Authors would like to thank Ujesh Vora for assisting the data collection in the laboratory. 
Reference

Anal, A. K., \& Singh, H. (2007). Recent advances in microencapsulation of probiotics for industrial applications and targeted delivery. Trends in Food Science \& Technology, 18(5), 240-251.

Augst, A. D., Kong, H. J., \& Mooney, D. J. (2006). Alginate hydrogels as biomaterials. Macromolecular bioscience, 6(8), 623-633.

Burey, P., Bhandari, B. R., Howes, T., \& Gidley, M. J. (2008). Hydrocolloid gel particles: formation, characterization, and application. Critical reviews in food science and nutrition, 48(5), 361-377.

Cabane, E., Zhang, X., Langowska, K., Palivan, C. G., \& Meier, W. (2012). Stimuli-responsive polymers and their applications in nanomedicine. Biointerphases, 7(1), 9 .

Chan, E. S., Lee, B. B., Ravindra, P., \& Poncelet, D. (2009). Prediction models for shape and size of ca-alginate macrobeads produced through extrusion-dripping method. Journal of colloid and interface science, 338(1), 63-72.

Collins, P. J., Houghton, L. A., Read, N. W., Horowitz, M., Chatterton, B. E., Heddle, R., \& Dent, J. (1991). Role of the proximal and distal stomach in mixed solid and liquid meal emptying. Gut, 32(6), 615-619.

Drusch, S. (2007). Sugar beet pectin: A novel emulsifying wall component for microencapsulation of lipophilic food ingredients by spray-drying. Food Hydrocolloids, 21(7), 1223-1228. 
Geankoplis, C.J. 2003. Transport Processes and Separation Process Principles. Pearson Education Inc.

Guerra, A., Etienne-Mesmin, L., Livrelli, V., Denis, S., Blanquet-Diot, S., \& Alric, M. (2012). Relevance and challenges in modeling human gastric and small intestinal digestion. Trends in biotechnology, 30(11), 591-600.

Higuita-Castro, N., Gallego-Perez, D., Love, K., Sands, M. R., Kaletunç, G., \& Hansford, D. J. (2012). Soft Lithography-Based Fabrication of Biopolymer Microparticles for Nutrient Microencapsulation. Industrial Biotechnology, 8(6), 365-371.

Kaletunç, G., Normand, M. D., Johnson E.A., \& Peleg, M. (1991a). "Degree of elasticity” determination in solid foods. Journal of food science, 56(4), 950-953.

Kaletunç, G., Normand, M. D., Nussinovitch, A., \& Peleg, M. (1991b). Determination of elasticity of gels by successive compression-decompression cycles. Food hydrocolloids, 5(3), 237-247.

Kaletunç, G. (2007). Prediction of specific heat of cereal flours: A quantitative empirical correlation. Journal of food engineering, 82(4), 589-594.

Kong, F., \& Singh, R. P. (2008). Disintegration of solid foods in human stomach. Journal of food science, 73(5), R67-R80.

Kuang, S. S., Oliveira, J. C., \& Crean, A. M. (2010). Microencapsulation as a tool for incorporating bioactive ingredients into food. Critical reviews in food science and nutrition, 50(10), 951-968. 
Madziva, H., Kailasapathy, K., \& Phillips, M. (2005). Alginate-pectin microcapsules as a potential for folic acid delivery in foods. Journal of microencapsulation, 22(4), 343-351.

Montgomery, D. C. (2008). Design and analysis of experiments. John Wiley \& Sons.

Morris, V. J., \& Chilvers, G. R. (1984). Cold setting alginate-pectin mixed gels. Journal of the Science of Food and Agriculture, 35(12), 1370-1376.

Oakenfull, D., \& Scott, A. (1984). Hydrophobic interaction in the gelation of high methoxyl pectins. Journal of Food Science, 49(4), 1093-1098.

Peppas, N. A., Hilt, J. Z., Khademhosseini, A., \& Langer, R. (2006). Hydrogels in biology and medicine: from molecular principles to bionanotechnology. Advanced Materials-Deerfield Beach Then Weinheim-, 18(11), 1345.

Rao, M. A., \& Cooley, H. J. (1995). Rates of structure development during gelation and softening of high-methoxyl pectin—sodium alginate—-fructose mixtures. Food hydrocolloids, 9(4), 229-235.

Ré M. I., Santana, M. H. A. \& d'Avila M. A. (2009). Chapter 7: Encapsulation Technologies for Modifying Food Performance. In Passos, M. L., \& Ribeiro, C. P. Editor (Eds.). Innovation in food engineering: New techniques and products. CRC Press.

SAS Institute. (2015). JMP® 12 fitting linear models. SAS Institute Inc.

Thakur, B. R., Singh, R. K., Handa, A. K., \& Rao, M. A. (1997). Chemistry and uses of pectina review. Critical Reviews in Food Science \& Nutrition, 37(1), 47-73. 
Thom, D., Dea, I. C. M., Morris, E. R., \& Powell, D. A. (1982). Interchain associations of alginate and pectins. Prog. Food Nutr. Sci, 6, 97-108.

Toft, K. (1982). Interactions between pectins and alginates. Prog. Food Nutr. Sci, 6, 89-96.

Toft, K., Grasdalen, H., \& Smidsrod, O. (1986). Synergistic gelation of alginates and pectins. In ACS Symposium series-American Chemical Society (USA).

U.S. Food and Drug Administration (FDA). (2015). Generally Recognized as Safe (GRAS). Retrieved from http://www.fda.gov/Food/IngredientsPackagingLabeling/GRAS/.

Walkenström, P., Kidman, S., Hermansson, A. M., Rasmussen, P. B., \& Hoegh, L. (2003). Microstructure and rheological behaviour of alginate/pectin mixed gels. Food Hydrocolloids, 17(5), 593-603.

Walther, B., Hamberg, L., Walkenström, P., \& Hermansson, A. M. (2004). Formation of shaped drops in a fast continuous flow process. Journal of colloid and interface science, 270(1), 195-204.

Wang, Y., Bamdad, F., Song, Y., \& Chen, L. (2012). Hydrogel particles and other novel proteinbased methods for food ingredient and nutraceutical delivery systems. Encapsulation technologies and delivery systems for food ingredients and nutraceuticals, 412-450. 


\section{Figure Legends}

Figure 1. Spherical and disc shape Al-P hydrogel particles produced under various parameters. a. 2.8\% TGC 43:57 wt\% Al-P spherical particle, b. 2.8\% TGC 43:57 wt\% Al-P disc particle top view, c. $2.8 \%$ TGC 43:57 wt\% Al-P disc particle side view.

Figure 2. Alginate and pectin structure at low and high $\mathrm{pH}$ showing that the $\mathrm{COO}^{-}$groups of alginate chain and $\mathrm{COOCH}_{2}^{-}$groups of pectin chain are protonated at low $\mathrm{pH}$. At high $\mathrm{pH}$, both groups then deprotonated back to ion form.

Figure 3 a. Total work as a function of successive compression- decompression cycles for $2.2 \%$

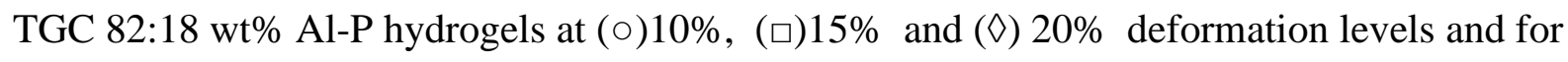



Figure 3 b. Percent recoverable work as a function of successive compression- decompression cycles for $2.2 \%$ TGC 82:18 wt $\%$ Al-P gels at (०)10\%, ( $\square) 15 \%$ and ( $\diamond) 20 \%$ deformation levels and for 2.8\% TGC 43:57 wt $\%$ Al-P gels at $(\bullet) 10 \%,(\boldsymbol{\bullet}) 15 \%$ and $(\bullet) 20 \%$ deformation levels.

Figure 4. Volume change of hydrogel particles as a function of time at $37{ }^{\circ} \mathrm{C}$ for a. $2.2 \%$ TGC 82:18 wt $\%$ Al to $\mathrm{P}$ ratio disc shape hydrogel particles at pH $3.0(\bullet), 5.0(\bullet)$ and $7.0(\bullet)$. b. $2.8 \%$ TGC 43:57 wt\% Al to P ratio disc shape hydrogel particles at $\mathrm{pH} 3.0(\mathrm{O}), 5.0(\mathrm{O})$ and $7.0(\mathrm{O})$. Solid lines represent the fitted data to zero-order kinetic model.

Figure 5. Volume change of hydrogel particles as a function of time over a three week storage

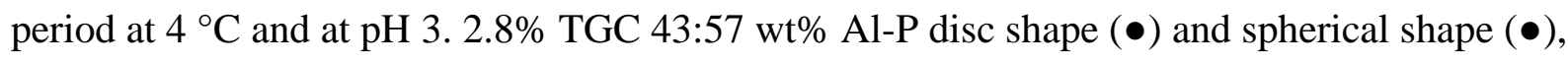
2.2\% TGC 82:18 wt\% Al-P disc shape (ש) and spherical shape (ש). 
Figure 6. Volume change of hydrogel particles as a function of time at $\mathrm{pH} 7.0$ for a. $2.8 \%$ TGC 43:57 wt\% Al-P, disc shape hydrogel particles at $4{ }^{\circ} \mathrm{C}(\bullet), 24{ }^{\circ} \mathrm{C}(\bullet)$, and $37^{\circ} \mathrm{C}(\bullet)$. b. $2.8 \%$ TGC 43:57 wt $\%$ Al-P, spherical hydrogel particles at $4{ }^{\circ} \mathrm{C}(\mathrm{\circ}), 24{ }^{\circ} \mathrm{C}(\mathrm{O})$, and $37{ }^{\circ} \mathrm{C}(\mathrm{\circ})$. Solid lines represent the fitted data to zero-order kinetic model.

Figure 7 Dissolution of a hydrogel particle for 2.2\% TGC 82:18 wt\% Al-P spherical shape at pH 5.0 and at $4{ }^{\circ} \mathrm{C}$ as a function of time. The red color was used for demonstration of hydrogel particle size change.

Figure 8. Calculated volume change using Eq. (9) versus experimental volume change for 24 sets of data collected from various combinations of F1 and F2 formulations, spherical and disc shape particles, at $\mathrm{pH} 5$ and 7 , and at temperatures of 4,24 , and $37{ }^{\circ} \mathrm{C}$. 
Table 1. Mechanical properties of the alginate: pectin gels prepared in $\mathrm{pH} 1.2$ curing bath.

\begin{tabular}{lccccc}
\hline Gel ratio & TGC & Strength $(\mathrm{kPa})$ & Strain at failure & Modulus $(\mathrm{kPa})$ & Work $\left(\mathrm{kJ} / \mathrm{m}^{3}\right)$ \\
\hline $43: 57 \mathrm{wt} \%$ Al-P & $2.8 \%$ & $480.50 \pm 8.41^{\mathrm{a}}$ & $0.79 \pm 0.02^{\mathrm{a}}$ & $93.63 \pm 7.20^{\mathrm{a}}$ & $131.24 \pm 5.12^{\mathrm{a}}$ \\
& $2.2 \%$ & $466.05 \pm 3.04^{\mathrm{a}}$ & $1.00 \pm 0.01^{\mathrm{b}}$ & $86.55 \pm 8.41^{\mathrm{a}}$ & $162.38 \pm 1.61^{\mathrm{b}}$ \\
& & & & & \\
$82: 18 \mathrm{wt} \%$ Al-P & $2.8 \%$ & $418.53 \pm 12.25^{\mathrm{b}}$ & $0.76 \pm 0.01^{\mathrm{a}}$ & $120.95 \pm 15.77^{\mathrm{b}}$ & $119.13 \pm 2.18^{\mathrm{a}}$ \\
& $2.2 \%$ & $408.76 \pm 14.52^{\mathrm{b}}$ & $0.85 \pm 0.05^{\mathrm{b}}$ & $83.67 \pm 10.86^{\mathrm{a}}$ & $169.65 \pm 3.04^{\mathrm{b}}$ \\
& & & & & \\
\hline
\end{tabular}

$\overline{\mathrm{a}, \mathrm{b}}$ Levels not connected by the same letter are significantly different at $\alpha=0.05$. 
Table 2. Volume dissolution rate constants under various $\mathrm{pH}$ and temperature conditions.

\begin{tabular}{|c|c|c|c|c|}
\hline \multirow[b]{3}{*}{ Shape } & \multirow[b]{3}{*}{$\mathrm{pH}$} & \multirow{3}{*}{$\begin{array}{l}\text { Temperature } \\
\left({ }^{\circ} \mathrm{C}\right)\end{array}$} & \multicolumn{2}{|c|}{ Volume dissolution rate constant $\mathrm{X} 10^{3}\left(\mathrm{~mm}^{3} / \mathrm{s}\right)$} \\
\hline & & & $2.2 \%$ TGC $82: 18 \mathrm{wt} \%$ & 2.8\% TGC 43:57 wt $\%$ \\
\hline & & & Al-P (F1) hydrogel particle & Al-P (F2) hydrogel particles \\
\hline \multirow[t]{6}{*}{ Disc } & pH 5.0 & 4 & $4.79 \pm 0.14$ & $7.95 \pm 0.10$ \\
\hline & & 24 & $14.19 \pm 1.64$ & $29.54 \pm 1.86$ \\
\hline & & 37 & $17.96 \pm 0.60$ & $43.92 \pm 1.27$ \\
\hline & $\mathrm{pH} 7.0$ & 4 & $6.49 \pm 0.15$ & $10.50 \pm 0.43$ \\
\hline & & 24 & $16.37 \pm 0.22$ & $45.12 \pm 1.77$ \\
\hline & & 37 & $25.97 \pm 1.48$ & $65.47 \pm 1.11$ \\
\hline \multirow[t]{6}{*}{ Sphere } & pH 5.0 & 4 & $3.84 \pm 0.38$ & $5.55 \pm 0.43$ \\
\hline & & 24 & $9.68 \pm 1.67$ & $15.44 \pm 0.34$ \\
\hline & & 37 & $15.10 \pm 0.49$ & $27.94 \pm 0.51$ \\
\hline & pH 7.0 & 4 & $4.24 \pm 0.76$ & $5.74 \pm 0.19$ \\
\hline & & 24 & $11.95 \pm 2.85$ & $16.29 \pm 0.54$ \\
\hline & & 37 & $15.95 \pm 0.83$ & $33.11 \pm 0.76$ \\
\hline
\end{tabular}


Table 3. Comparison of the dimensional dissolution rate constants for the spherical and disc shaped hydrogel particles.

\section{Dissolution rate constant $\times 10^{3}(\mathrm{~mm} / \mathrm{s})$}

2.2\% TGC 82:18 Al-P (F1) particles

Disc particles
Spherical particles
2.8\% TGC 43:57 Al-P (F2) particles

Disc particles

Spherical particles

$\mathrm{T}$

\begin{tabular}{cccccccc}
$\mathrm{pH}$ & $\left({ }^{\circ} \mathrm{C}\right)$ & Thickness & Diameter & Diameter & Thickness & Diameter & Diameter \\
\hline 5.0 & 4 & $0.47 \pm 0.006^{*}$ & $0.66 \pm 0.05^{*, * *}$ & $0.48 \pm 0.05^{* *}$ & $0.51 \pm 0.01^{*}$ & $0.90 \pm 0.04^{*, * *}$ & $0.72 \pm 0.05^{* *}$ \\
& 24 & $1.16 \pm 0.08^{*}$ & $2.07 \pm 0.32^{*, * *}$ & $1.26 \pm 0.08^{* *}$ & $2.20 \pm 0.03^{*}$ & $3.46 \pm 0.24^{*, * *}$ & $1.71 \pm 0.04^{* *}$ \\
& 37 & $1.78 \pm 0.04^{*}$ & $3.30 \pm 0.14^{*, * *}$ & $1.69 \pm 0.07^{* *}$ & $3.21 \pm 0.10^{*}$ & $4.60 \pm 0.68^{* * *}$ & $3.58 \pm 0.07^{* *}$ \\
7.0 & 4 & $0.42 \pm 0.04^{*}$ & $0.90 \pm 0.01^{*, * *}$ & $0.59 \pm 0.05^{* *}$ & $0.69 \pm 0.06^{*}$ & $0.97 \pm 0.15^{*, * *}$ & $0.77 \pm 0.02^{* *}$ \\
& 24 & $1.35 \pm 0.02^{*}$ & $2.06 \pm 0.02^{*, * *}$ & $1.49 \pm 0.22^{* *}$ & $3.01 \pm 0.06^{*}$ & $5.35 \pm 0.39^{*, * *}$ & $1.73 \pm 0.02^{* *}$ \\
& 37 & $2.61 \pm 0.05^{*}$ & $3.29 \pm 0.17^{*, * *}$ & $2.00 \pm 0.04^{* *}$ & $4.53 \pm 0.49^{*}$ & $8.37 \pm 0.39^{*, * *}$ & $3.38 \pm 0.09^{* *}$
\end{tabular}

* Significant difference existed between the thickness and diameter dissolution rate constants of disc particles at $\alpha=0.05$.

** Significant difference between the diameter dissolution rate constants existed for the disc and spherical particles at $\alpha=0.05$. 
Table 4. Activation energy and frequency factor determined by nonlinear fit for various $\mathrm{pH}$, alginate: pectin ratio and particle shapes.

Volume Activation frequency factor

Energy $\quad\left(\mathrm{mm}^{3} / \mathrm{s}\right)$

Level

$(\mathrm{kJ} / \mathrm{mol})$

2.8\% TGC 43:57 wt\% Al-P (F2) disc particle $\mathrm{pH} 7.0$

$39.02 \pm 0.94^{\mathrm{a}}$

$27686 \pm 1183$

2.8\% TGC 43:57 wt\% Al-P (F2) disc particle $\mathrm{pH} 5.0$

$38.35 \pm 1.60^{\mathrm{a}, \mathrm{b}}$

$13464 \pm 4805$

2.8\% TGC 43:57 wt \% Al-P (F2) spherical particle $\mathrm{pH} 7.0 \quad 35.38 \pm 0.83^{\mathrm{b}, \mathrm{c}}$

$244678 \pm 12334$

2.8\% TGC 43:57 wt\% Al-P (F2) spherical particle pH 5.0 $33.81 \pm 1.23^{\mathrm{c}, \mathrm{d}}$

$133406 \pm 10292$

2.2\% TGC 82:18 wt\% Al-P (F1) disc particle pH 7.0

$30.45 \pm 1.75^{\mathrm{d}, \mathrm{e}}$

$2261 \pm 304$

2.2\% TGC 82:18 wt\% Al-P (F1) spherical particle $\mathrm{pH} 5.0 \quad 30.09 \pm 0.94^{\mathrm{e}}$

$727 \pm 101$

$2.2 \%$ TGC $82: 18$ wt $\%$ Al-P (F1) spherical particle $p H 7.0 \quad 27.75 \pm 1.53^{\mathrm{e}}$

$2956 \pm 290$

2.2\% TGC 82:18 wt\% Al-P (F1) disc particle $\mathrm{pH} 5.0$

$27.11 \pm 0.83^{\mathrm{e}}$

$664 \pm 37$

Levels not connected by same letter are significantly different at $\alpha=0.05$. 
Figure 1a

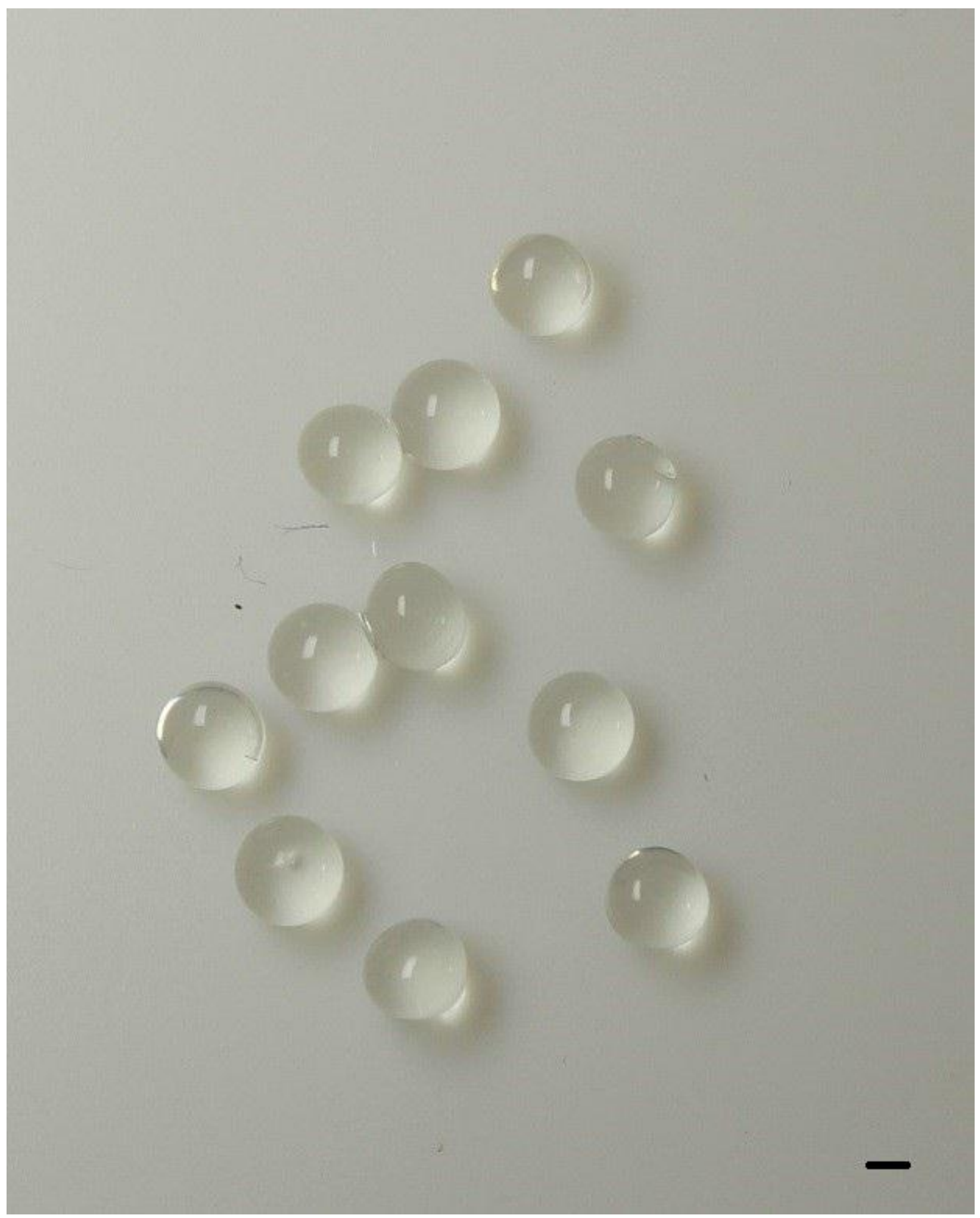


Figure 1b

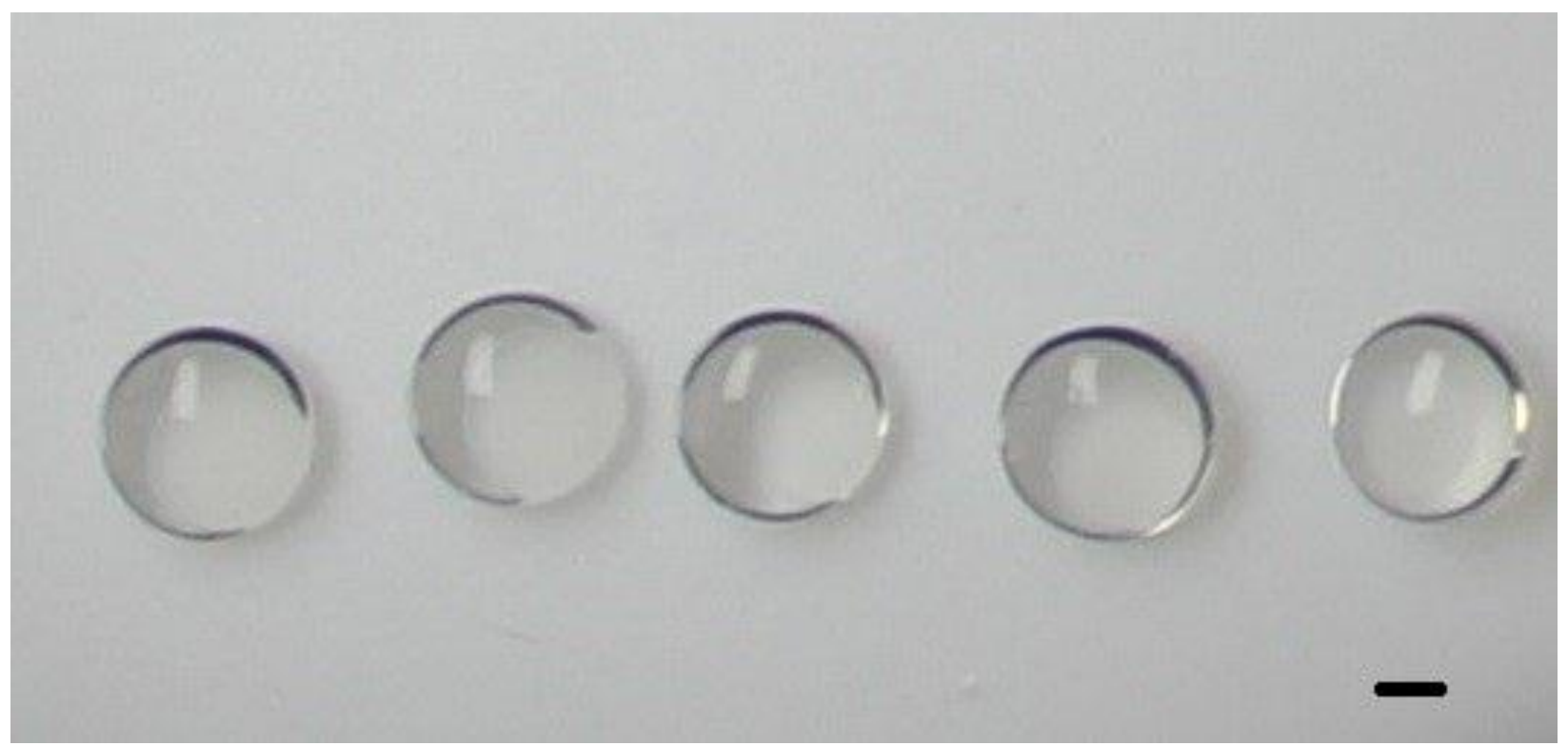


Figure 1c




Figure 2

Low pH



High $\mathrm{pH}$

$\widehat{\vartheta}$

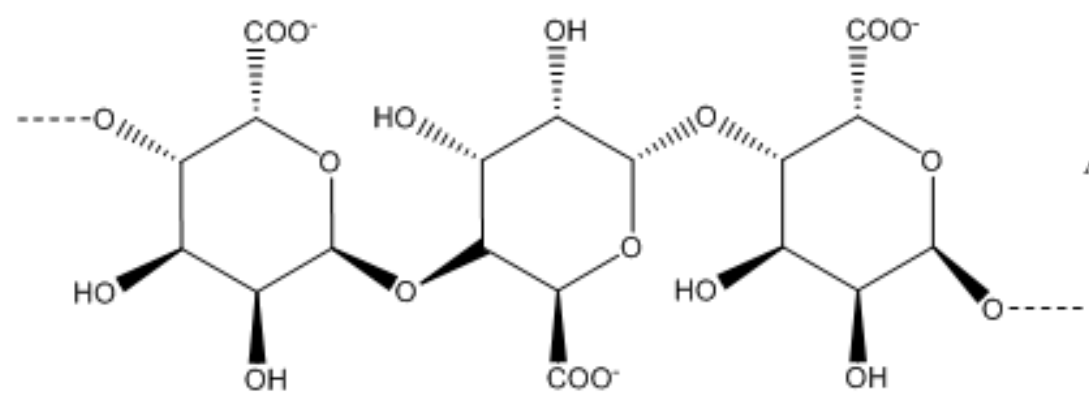

Alginate (Guluronic acid)




Figure 3 a




Figure $3 b$

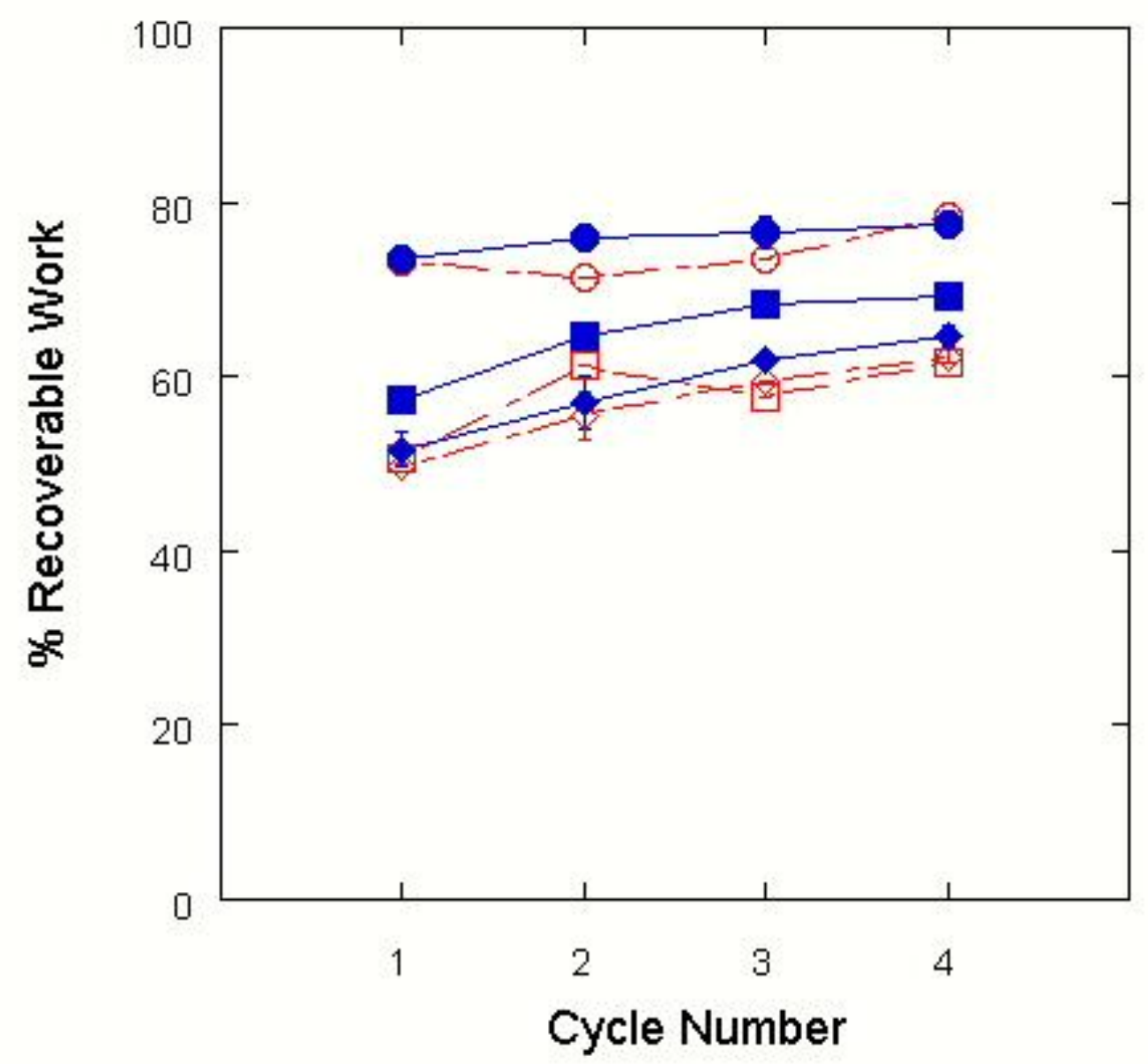


Figure 4 a

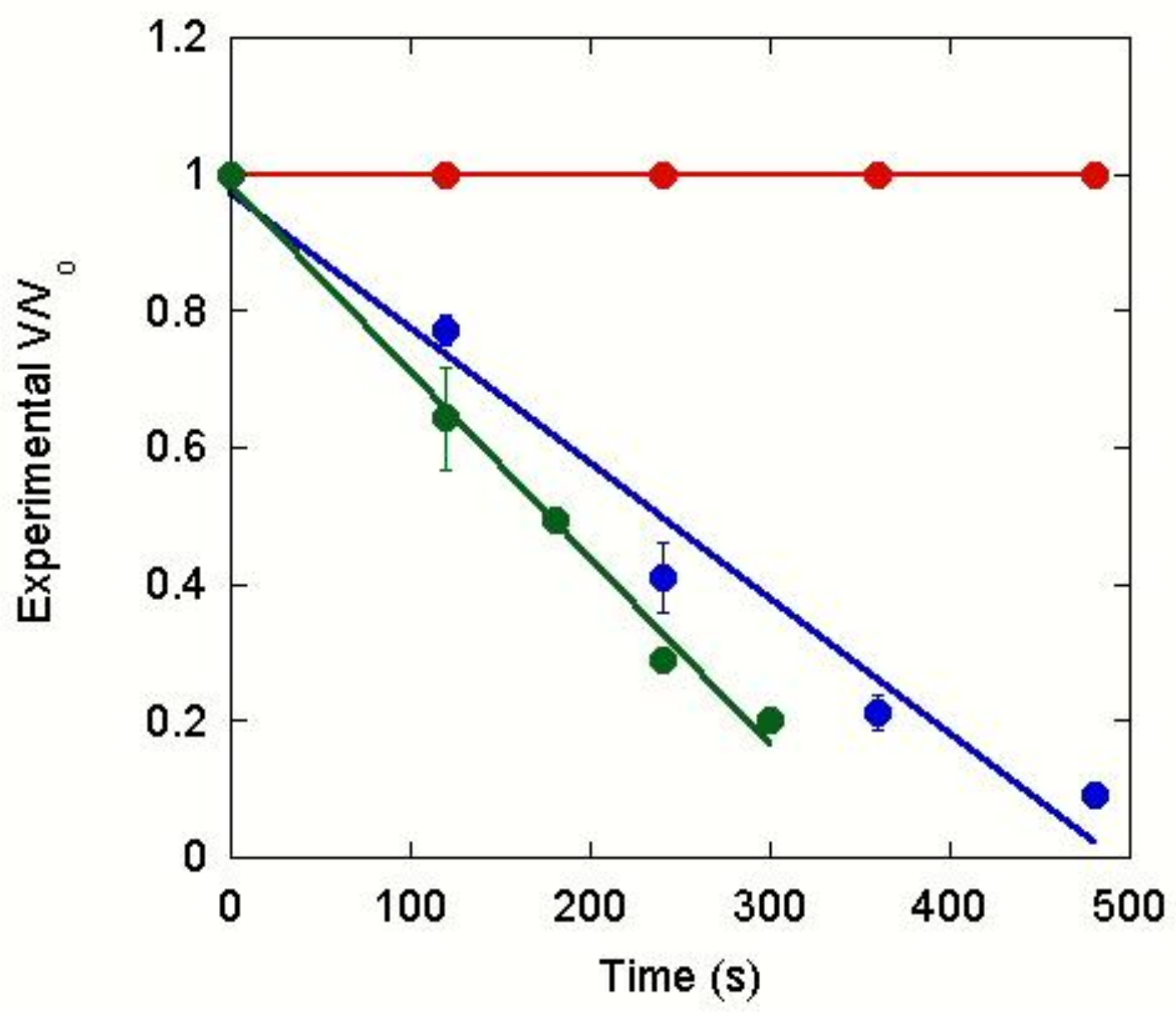


Figure 4 b

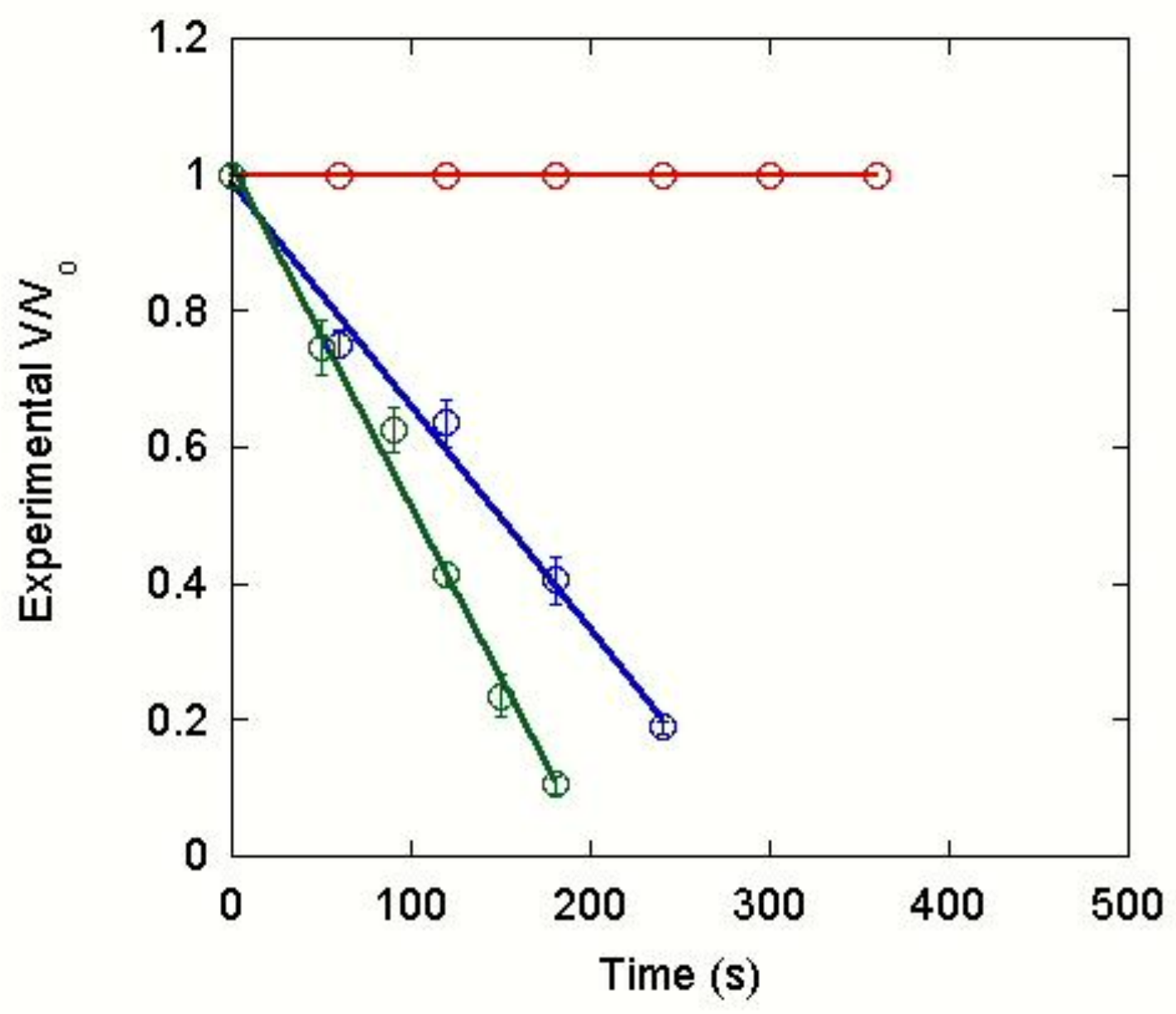


Figure 5

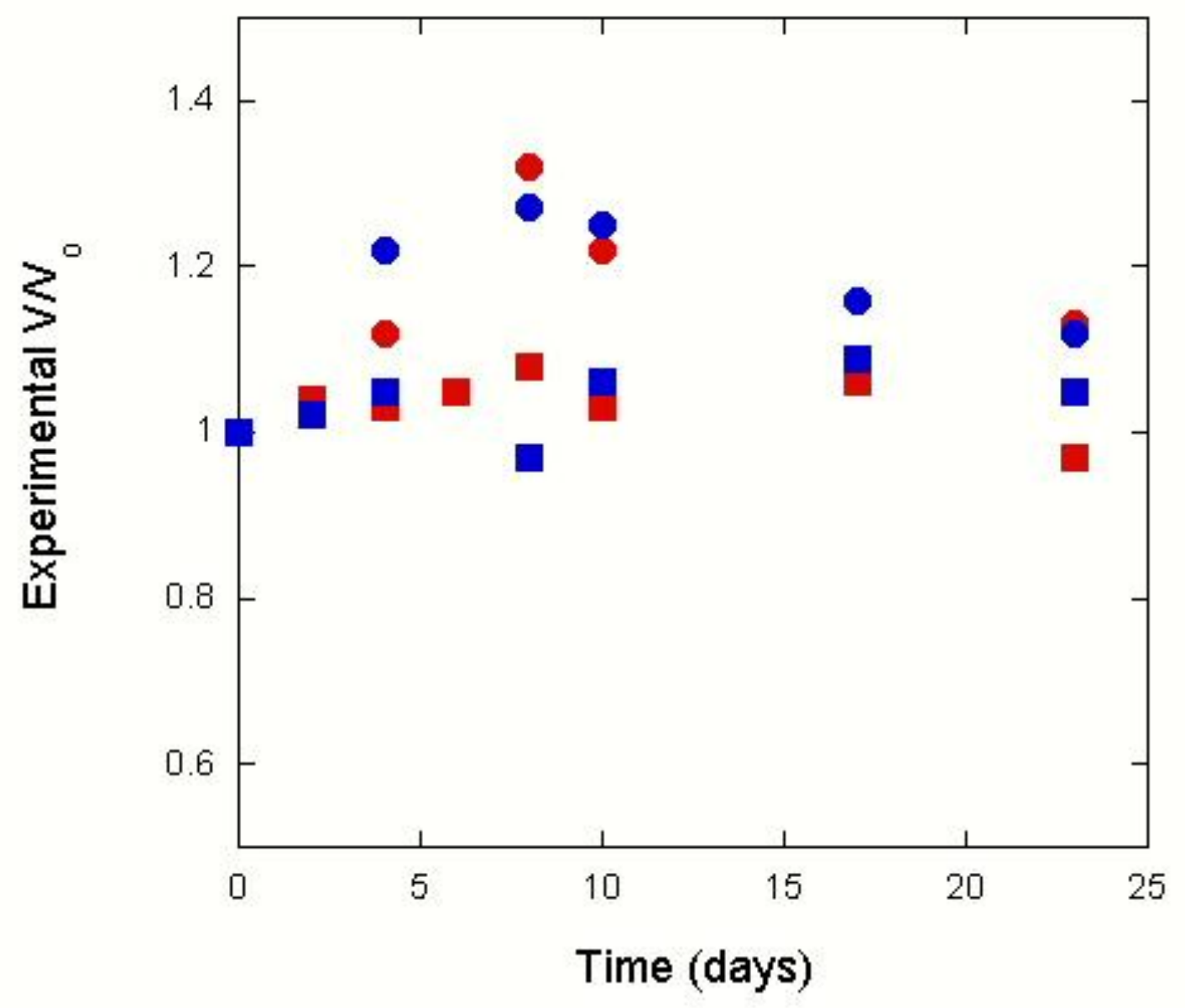


Figure 6 a

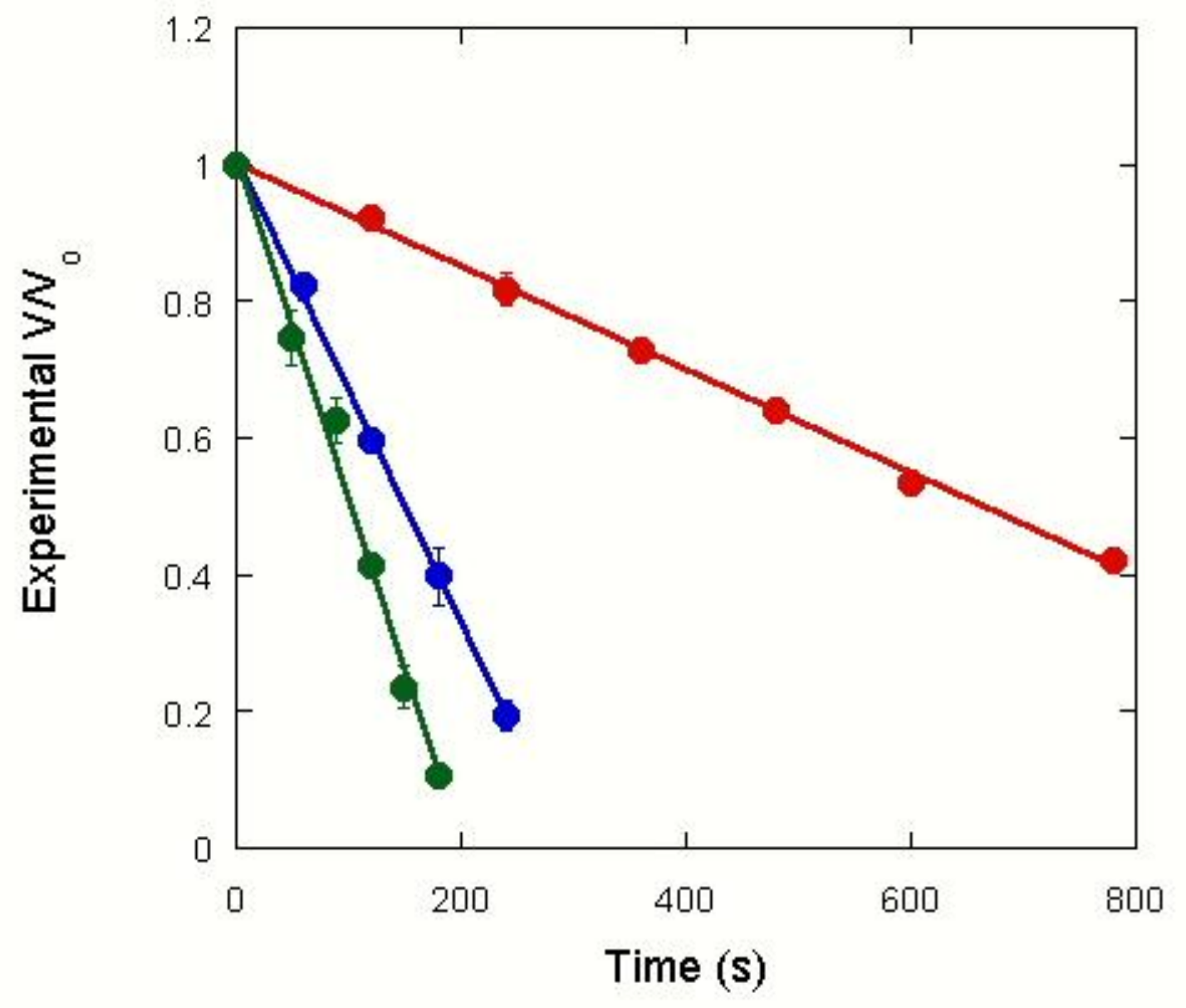


Figure $6 b$

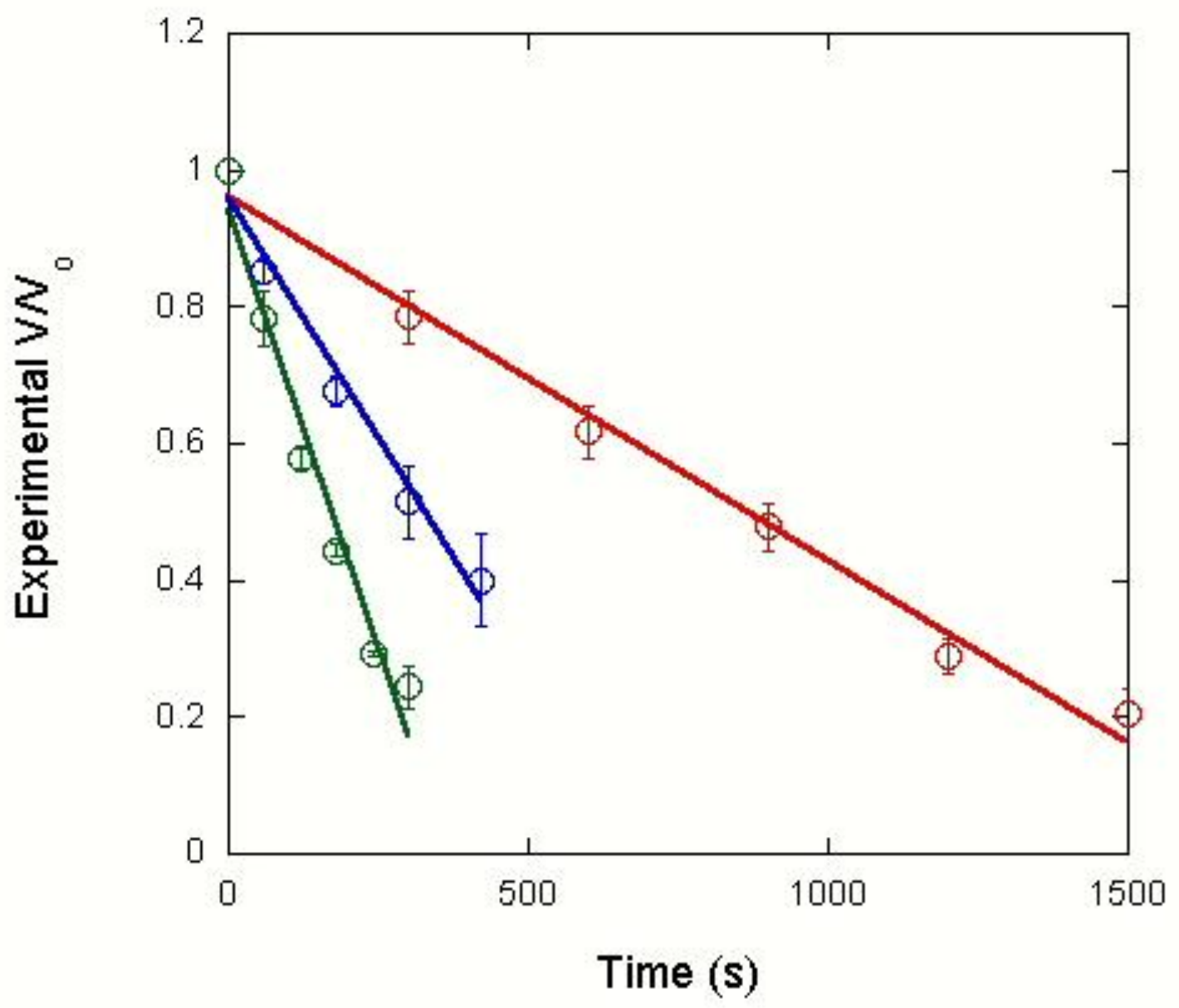


Figure 7
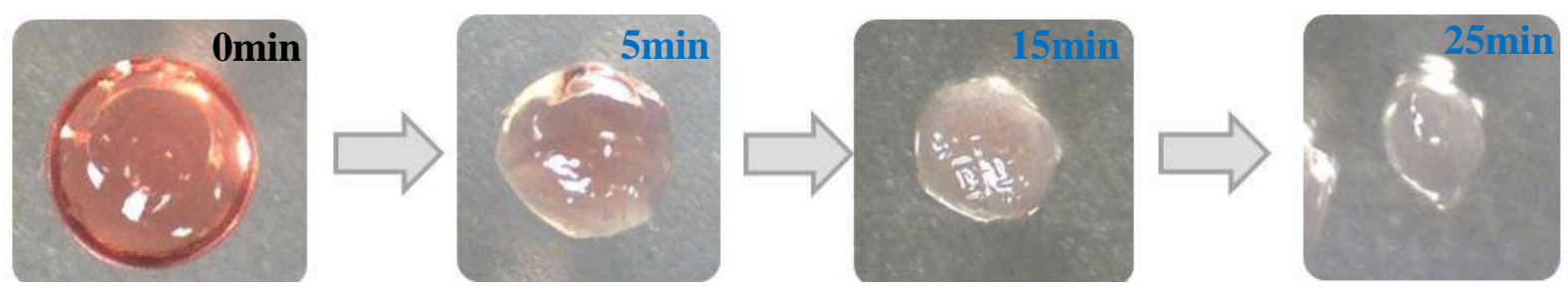
Figure 8

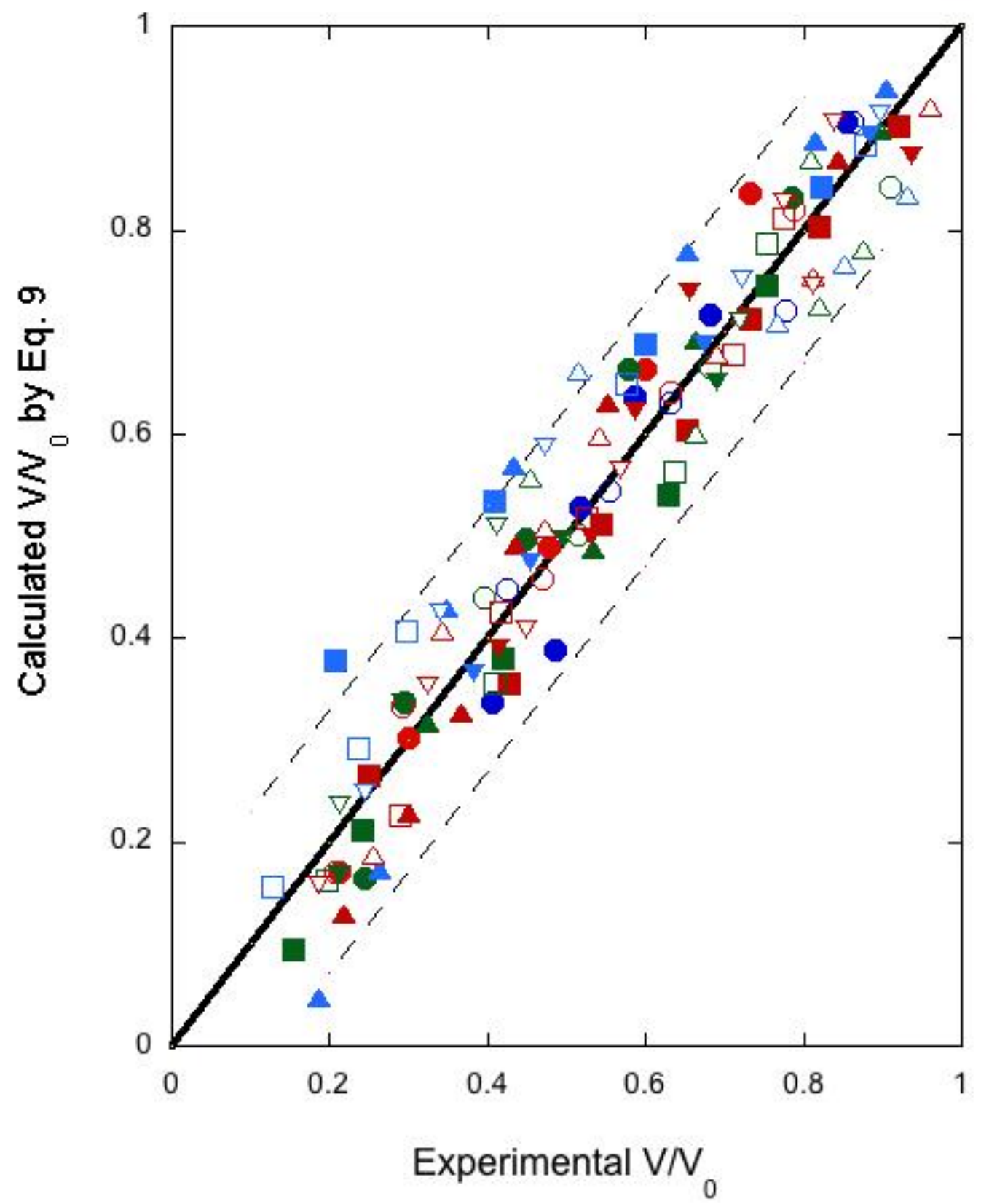

